Author affiliations and support information (if applicable) appear at the end of this article.

Published at jco.org on February 6, 2017 Corresponding author: Juhua Luo, PhD, Department of Epidemiology and Biostatistics, School of Public Health, Indiana University, $1025 \mathrm{E} 7$ th St, Bloomington, IN 47405; e-mail: juhluo@ indiana.edu.

(c) 2017 by American Society of Clinical Oncology

0732-183X/17/3511w-1189w/\$20.00

\title{
Intentional Weight Loss and Endometrial Cancer Risk
}

Juhua Luo, Rowan T. Chlebowski, Michael Hendryx, Thomas Rohan, Jean Wactawski-Wende, Cynthia A. Thomson, Ashley S. Felix, Chu Chen, Wendy Barrington, Mace Coday, Marcia Stefanick, Erin LeBlanc, and Karen L. Margolis

\section{$\begin{array}{llllllll}\text { A } & \text { B } & \mathbf{S} & \mathbf{T} & \mathbf{R} & \mathbf{A} & \mathbf{C} & \mathbf{T}\end{array}$}

\section{Purpose}

Although obesity is an established endometrial cancer risk factor, information about the influence of weight loss on endometrial cancer risk in postmenopausal women is limited. Therefore, we evaluated associations among weight change by intentionality with endometrial cancer in the Women's Health Initiative (WHI) observational study.

\section{Patients and Methods}

Postmenopausal women $(\mathrm{N}=36,794)$ ages 50 to 79 years at $\mathrm{WHI}$ enrollment had their body weights measured and body mass indices calculated at baseline and at year 3 . Weight change during that period was categorized as follows: stable (change within $\pm 5 \%$ ), loss (change $\geq 5 \%$ ), and gain (change $\geq 5 \%$ ). Weight loss intentionality was assessed via self-report at year 3; change was characterized as intentional or unintentional. During the subsequent 11.4 years (mean) of follow-up, 566 incident endometrial cancer occurrences were confirmed by medical record review. Multivariable Cox proportional hazards regression models were used to evaluate relationships (hazard ratios [HRs] and $95 \% \mathrm{Cls}$ ) between weight change and endometrial cancer incidence.

\section{Results}

In multivariable analyses, compared with women who had stable weight ( $\pm 5 \%$ ), women with weight loss had a significantly lower endometrial cancer risk ( $\mathrm{HR}, 0.71 ; 95 \% \mathrm{Cl}, 0.54$ to 0.95$)$. The association was strongest among obese women with intentional weight loss $(\mathrm{HR}, 0.44 ; 95 \% \mathrm{Cl}$, 0.25 to 0.78 ). Weight gain ( $\geq 10$ pounds) was associated with a higher endometrial cancer risk than was stable weight, especially among women who had never used hormones.

\section{Conclusion}

Intentional weight loss in postmenopausal women is associated with a lower endometrial cancer risk, especially among women with obesity. These findings should motivate programs for weight loss in obese postmenopausal women.

\section{J Clin Oncol 35:1189-1193. (C) 2017 by American Society of Clinical Oncology}

\section{INTRODUCTION}

Endometrial cancer is the most common gynecologic cancer and the fourth most common cancer among women in the United States. ${ }^{1} \mathrm{Al}-$ though endometrial cancer is the cancer most strongly associated with obesity, ${ }^{2}$ information about the effects of weight loss in postmenopausal women on subsequent endometrial cancer incidence is limited. Several observational studies have associated self-reported weight loss at some period during adult life with lower endometrial cancer risk. ${ }^{3-6}$ However, these reports have not focused on weight loss that occurred in postmenopausal women or on the potential influence of intentionality of weight loss on risk.
Unintentional weight loss is highly correlated with increased morbidity and may contribute to reverse causality. ${ }^{7,8}$ To our review, the issue of the influence of intentional weight loss on endometrial cancer risk has only been addressed in one prospective study - the Iowa Women's Health Study. ${ }^{3}$ In that study, women who experienced a previous episode, anytime during adult life, of intentional, self-reported weight loss of greater than 20 pounds and who were not currently overweight had endometrial cancer risks similar to those of nonoverweight women who never lost weight.

The Women's Health Initiative (WHI) observational study, which measured serial weights with an associated query about weight loss intentionality, provides a unique opportunity 
to evaluate the association of weight change and endometrial cancer risk by weight loss intentionality among an ethnically diverse population of postmenopausal women.

\section{PATIENTS AND METHODS}

\section{WHI}

The WHI was designed to address major causes of morbidity and mortality in postmenopausal women ${ }^{9}$ and included both a set of clinical trials and an observational study. Details of design and implementation of the WHI program have been published elsewhere. ${ }^{10-14}$ Briefly, 161,808 women ages 50 to 79 years with anticipated survival greater than 3 years were recruited at 40 clinical centers throughout the United States between September 1, 1993, and December 31, 1998. Participants in the observational study included 93,676 women who were ineligible or uninterested in participating in the clinical trials. The study was approved by institutional review boards at the clinical centers, and participants provided written informed consent.

Information on covariates of interest was collected from questionnaires administered at baseline. Information on menopausal hormone therapy use was collected during interviews that included a review of medication containers. Race/ethnicity was documented by self-report at baseline. Weight and height were measured by using a standardized approach at clinic visits, and body mass index (BMI) was calculated.

The following participants were excluded from the cohort for this analysis: women who had a history of cancer (except for non-melanoma skin cancer; $\mathrm{n}=10,197$ ) at baseline; women who were enrolled in the WHI but provided no follow-up information $(\mathrm{n}=422)$; women who had undergone hysterectomy before enrollment $(\mathrm{n}=33,317)$; women who had a missing value of exposures of interest and major confounders $(n=11,081)$; women whose BMI was less than $18.5 \mathrm{~kg} / \mathrm{m}^{2}$ (underweight; $\mathrm{n}=837$ ); and women who had an endometrial cancer diagnosis, had a hysterectomy, died, or were lost to follow-up between baseline and the year-3 visit $(n=1,029)$. After exclusions, 36,793 women remained for additional analysis.

\section{Follow-Up and Ascertainment of Cases}

Follow-up continued through the original specified completion date of March 31, 2005. Additional follow-up required two additional written consents, which were obtained in $78 \%$ of surviving participants.

All incident endometrial cancer occurrences diagnosed after the year-3 visit were the primary study outcome. Endometrial cancer occurrences were initially identified by selfreport from questionnaires administered annually, confirmed by medical record review, and coded centrally at the clinical coordinating center according to the SEER guidelines. For these analyses, participants were observed from the year- 3 visit to the first of either an endometrial cancer diagnosis, a date of hysterectomy, a date of death, loss to follow-up, or end of current follow-up (September 30, 2015).

\section{Measurements}

Weight change between baseline and year 3 was calculated from the measured weights and was grouped into three categories: stable weight, weight loss, or weight gain. The three categories were defined in two ways: on the basis of an actual change in body weight (stable weight, or change within \pm 10 pounds; weight loss $\geq 10$ pounds from baseline weight; and weight gain $\geq 10$ pounds from baseline weight) and on the basis of percentage change in body weight (stable weight, or change within $\pm 5 \%$; weight loss $\geq 5 \%$ from baseline; and weight gain $\geq 5 \%$ from baseline).

In addition, at the year-3 year follow-up, women were asked in a questionnaire "In the past 2 years, did you gain or lose 5 or more pounds?" and "Was the change intentional or unintentional?" The information was used to categorize weight loss as intentional or unintentional.

\section{Covariates}

We adjusted for the following potential confounders measured at baseline: age ( $<55,55$ to 59,60 to 64,65 to 69,70 to 74 , and $\geq 75$ years), race/ethnicity (American Indian or Alaska Native, Asian or Pacific Islander, Black, Hispanic/Latino, nonHispanic white, and other), level of education (high school or less, some college/technical training, college or some postcollege, and master's degree or higher), smoking pack-years (never, $<10$, 10 to $<20,20$ to $<30,30$ to $<40$, and $\geq 40$ ), recreational physical activity (total metabolic equivalent tasks [METs] per week: $<5,5$ to $<10,10$ to $<20,20$ to $<30$, and $\geq 30$ ), history of hormone therapy use (none, estrogen alone, estrogen and progestin, mixed), parity (never pregnant, never had term, 1, 2, 3, 4, or $\geq 5$ ), age of menarche ( $<12,12$ to 13,14 to 15 , or $\geq 16$ years), age at first birth (never had term pregnant, $<20,20$ to 29 , or $\geq 30$ years), family history of endometrial cancer (yes or no), and BMI. Detailed information about the categorizations of each variable is listed in Table 1

\begin{tabular}{|c|c|c|}
\hline $\begin{array}{c}\text { Weight Change Between } \\
\text { Baseline and Year } 3\end{array}$ & $\begin{array}{l}\text { No. of } \\
\text { Patients }\end{array}$ & $\begin{array}{c}\text { Multivariable-Adjusted } \\
\text { HR }(95 \% \mathrm{Cl})^{*}\end{array}$ \\
\hline \multicolumn{3}{|l|}{ Change in pounds } \\
\hline Stable weight (within \pm 10 ) & 425 & Reference \\
\hline Weight gain $(\geq 10$ ) & 96 & 1.26 (1.00 to 1.57$)$ \\
\hline Weight loss $(\geq 10)$ & 45 & $0.70(0.51$ to 0.98$)$ \\
\hline Intentional & 27 & $0.61(0.40$ to 0.92$)$ \\
\hline Unintentional & 18 & 0.91 (0.56 to 1.46$)$ \\
\hline \multicolumn{3}{|l|}{$\%$ weight change } \\
\hline Stable weight (within \pm 5 ) & 384 & Reference \\
\hline Weight gain $(\geq 5)$ & 124 & 1.12 (0.92 to 1.38$)$ \\
\hline Weight loss $(\geq 5$ ) & 58 & $0.71(0.54$ to 0.95$)$ \\
\hline Intentional & 33 & $0.60(0.42$ to 0.86$)$ \\
\hline Unintentional & 25 & $0.94(0.62$ to 1.41$)$ \\
\hline
\end{tabular}

Abbreviation: HR, hazard ratio.

* Multivariable models adjusted for age at enrollment, race/ethnicity, education, smoking pack-years, recreational physical activity, history of hormone therapy use, parity, age of menarche, age at first birth, family history of endometrial cancer, and body mass index. 


\section{Statistical Analysis}

$\chi^{2}$ tests were used to evaluate differences for categoric covariates. An analysis of variance was used for continuous variables. Cox proportional hazards regression models were used to evaluate the relationship (hazard ratios [HRs] and 95\% CIs) between weight change and incidence of endometrial cancer. We also performed analyses of relationships between weight change and endometrial cancer risk stratified by obesity status, hormone use, and age at baseline. In the final multivariate-adjusted models, potential confounders included these variables listed in the Covariates section. Because obesity reportedly has a greater effect on type I endometrial cancer (endometrioid adenocarcinoma, adenocarcinoma not otherwise specified, or adenocarcinoma with squamous differentiation) than on type II endometrial cancer (serous/papillary serous and mixed-cell adenocarcinoma), ${ }^{15}$ we restricted sensitivity analyses to type I tumors. Our primary study hypothesis was that intentional weight loss would be significantly associated with a lower risk of endometrial cancer. We conducted another sensitivity analysis to test whether women who intentionally lost weight and had a lower BMI at 3 years had the same risk of endometrial cancer as women who had the same lower stable BMI (at baseline and 3 years) by analyzing the changes of BMI between baseline and year 3. The change of BMI was categorized as low-stable BMI (BMI $<25 \mathrm{~kg} / \mathrm{m}^{2}$ at baseline and year-3 visit: reference group); weight gain or stay-high BMI group (BMI $<25 \mathrm{~kg} / \mathrm{m}^{2}$ at baseline and BMI $\geq 25 \mathrm{~kg} / \mathrm{m}^{2}$ at year- 3 visit, or BMI $\geq 25 \mathrm{~kg} / \mathrm{m}^{2}$ at baseline and year- 3 visit); and weight loss group (BMI $\geq 25 \mathrm{~kg} / \mathrm{m}^{2}$ at baseline and BMI $<25 \mathrm{~kg} / \mathrm{m}^{2}$ at year-3 visit). We then divided the weight loss group intro intentional and unintentional.

\section{RESULTS}

During a mean 11.4 years of follow-up, 566 women developed endometrial cancer. Baseline characteristics by percentage of weight change categories from baseline to year 3 (stable weight [change within $\pm 5 \%]$ ), weight loss $\geq 5 \%$, and weight gain $\geq 5 \%$ ) are listed in Appendix Table A1 (online only). Compared with women who had stable weight, women who had weight gain were more likely to be younger, less physically active, black, less educated, and heavier smokers. They were also more likely to be hormone therapy users, have a younger age at menarche, have fewer term pregnancies, and have a younger age at first birth. Compared with women who had stable weight, women who had intentional weight loss were more likely to have a higher BMI, be less physically active, be black, be less educated, and be heavier smokers. They were also more likely to never have used hormone therapy, to have had a younger age at menarche, to have had a greater number of term pregnancies, and to have had a younger age at first birth (all $P<.05$ ).

After analyses were adjusted for baseline BMI and other potential confounders, women who had weight loss $\geq 5 \%$ had a significantly lower risk of endometrial cancer than women who had stable weight (HR, 0.71; 95\% CI, 0.54 to 0.95 ; Table 1). This was observed for any weight loss, but the risk was even lower for obese women who had intentional weight loss (HR, 0.44; 95\% CI, 0.25 to 0.78 ; Table 2). These results were similar regardless of weight change measured in pounds or percentage between baseline and year 3. Women with weight gain $\geq 10$ pounds had a significantly higher risk of endometrial cancer $(P=.049)$. Weight gain measured by percentage $(\geq 5 \%)$ was not associated with an endometrial cancer risk. Unintentional weight loss was not associated with a lower risk (Table 1).

We examined the associations between weight change and risk of endometrial cancer stratified by potential effect modifiers, including BMI (normal weight, overweight, and obese), menopausal hormone therapy use (never, ever estrogen alone users, or exclusively estrogen plus progestin users), and age at baseline (50 to 59,60 to $69, \geq 70$ years). We observed a significantly lower risk of endometrial cancer associated with weight loss among women who were obese but not in women who were normal weight or overweight (Table 2). There was a $48 \%$ lower risk seen for obese women who lost weight intentionally when weight change was measured in pounds (HR, 0.52; 95\% CI, 0.30 to 0.90 ), and a $56 \%$ lower risk when weight change was measured as a percentage (HR, $0.44 ; 95 \%$ CI, 0.25 to 0.78 ). The $P$ value for the interaction test was .07 when weight change was measured in pounds and was .10 when weight change was measured as a percentage.

\begin{tabular}{|c|c|c|c|c|c|c|}
\hline \multirow{2}{*}{$\begin{array}{c}\text { Weight Change Between } \\
\text { Baseline and Year } 3\end{array}$} & \multicolumn{2}{|c|}{$\begin{array}{l}\text { Normal Weight } \\
\text { (BMI } 18.5 \text { to }<25 \mathrm{~kg} / \mathrm{m} 2 \text { ) }\end{array}$} & \multicolumn{2}{|c|}{ Overweight (BMI 25 to $<30 \mathrm{~kg} / \mathrm{m} 2$ ) } & \multicolumn{2}{|c|}{ Obese (BMI $\geq 30 \mathrm{~kg} / \mathrm{m} 2)$} \\
\hline & No. of Patients & $\mathrm{HR}(95 \% \mathrm{CI})^{*}$ & No. of Patients & HR (95\% Cl) & No. of Patients & HR $(95 \% \mathrm{Cl})$ \\
\hline \multicolumn{7}{|l|}{ Change in pounds } \\
\hline Stable weight (within \pm 10 ) & 198 & Reference & 112 & Reference & 115 & reference \\
\hline Weight gain $(\geq 10)$ & 25 & $1.08(0.71$ to 1.64$)$ & 30 & 1.49 (0.99 to 2.24$)$ & 41 & $1.29(0.90$ to 1.86$)$ \\
\hline Weight loss ( $\geq 10$ ) & 5 & $0.59(0.24$ to 1.43$)$ & 18 & 1.36 (0.82 to 2.25$)$ & 22 & $0.53(0.33$ to 0.87$)$ \\
\hline Intentional & 2 & 0.52 (0.13 to 2.08$)$ & 9 & $1.04(0.52$ to 2.05$)$ & 16 & $0.52(0.30$ to 0.90$)$ \\
\hline Unintentional & 3 & $0.64(0.21$ to 2.02$)$ & 9 & 2.00 (1.01 to 3.96$)$ & 6 & $0.57(0.25$ to 1.33$)$ \\
\hline \multicolumn{7}{|l|}{$\%$ weight change } \\
\hline Stable weight (within $\pm 5 \%$ change) & 164 & Reference & 100 & Reference & 120 & Reference \\
\hline Weight gain $(\geq 5 \%)$ & 49 & $1.08(0.78$ to 1.49$)$ & 37 & $1.23(0.84$ to 1.80$)$ & 38 & $1.14(0.78$ to 1.65$)$ \\
\hline Weight loss ( $\geq 5 \%$ ) & 15 & $0.80(0.47$ to 1.35$)$ & 23 & $1.16(0.74$ to 1.83$)$ & 20 & $0.47(0.29$ to 0.77$)$ \\
\hline Intentional & 6 & $0.61(0.27$ to 1.38$)$ & 13 & $1.01(0.57$ to 1.81$)$ & 14 & $0.44(0.25$ to 0.78$)$ \\
\hline Unintentional & 9 & $1.00(0.51$ to 1.97$)$ & 10 & $1.44(0.75$ to 2.78$)$ & 6 & $0.57(0.25$ to 1.30$)$ \\
\hline
\end{tabular}

Abbreviations: BMI, body mass index; $\mathrm{HR}$, hazard ratio.

* Multivariable models adjusted for age at enrollment, race/ethnicity, education, smoking pack-years, recreational physical activity, history of hormone therapy use, parity, age of menarche, age at first birth, family history of endometrial cancer, and BMI (measured continuously and included as a covariate only for the obese group) 
We observed a higher risk of endometrial cancer associated with weight gain $\geq 10$ pounds in women without a history of menopausal hormone use but not in women with a history of hormone use (Table 3 ). We also observed a lower risk of endometrial cancer associated with intentional weight loss measured in pounds or as a percentage in women with a history of estrogen plus progestin use exclusively but not in women without hormone use or with estrogen alone use $(P$ for interaction test $=.02$ when weight change was measured in pounds; $P=.6$ when weight change was measured as a percentage). The association between weight change and endometrial cancer risk did not differ by age.

In a sensitivity analysis of weight loss and endometrial cancer subtypes, a stronger association was seen between intentional weight loss and risk of type I endometrial cancer compared with overall results. For example, compared with women who had stable weight $( \pm 5 \%)$, women who had intentional weight loss had a $52 \%$ lower risk of type I endometrial cancer (HR, $0.48 ; 95 \% \mathrm{CI}, 0.30$ to 0.76 ) overall; obese women who had intentional weight loss had a $74 \%$ lower risk compared with obese women with stable weight (HR, 0.26; 95\% CI, 0.12 to 0.57). The results from the second sensitivity analysis showed that women who intentionally lost weight and had a normal BMI at 3 years (ie, $<25 \mathrm{~kg} / \mathrm{m}^{2}$ ) had the same risk of endometrial cancer as women who maintained a stable normal BMI (Appendix Table A2, online only).

\section{DISCUSSION}

In this large prospective study of postmenopausal women, after analyses were adjusted for BMI and other potential confounders, intentional weight loss was associated with a lower risk of endometrial cancer, especially among obese women.

Previous studies ${ }^{3-6}$ that investigated the association between endometrial cancer and weight loss have considered weight change throughout adult life, without a focus on change during the postmenopausal period, and have been based on self-reported weights. One case-control study ${ }^{5}$ and one cohort study ${ }^{4}$ have associated self-reported weight loss with lower endometrial cancer risk. One case-control study ${ }^{6}$ reported that women who had intentionally lost weight and maintained that weight loss were not at a higher endometrial cancer risk than women who maintained a normal weight throughout. A similar result was also reported in the Iowa Women's Health Study. ${ }^{3}$

To our knowledge, this study is the first to use measured baseline and follow-up weights with weight loss intentionality examined over a relatively short period to temporally link measured weight change in postmenopausal women. In this setting, modest weight loss was associated with a significantly lower risk of endometrial cancer. Additionally, although intentional weight loss was associated with a significantly lower risk of endometrial cancer, unintentional weight loss was not. These findings suggest that, in postmenopausal women, it may not be too late for weight loss to offer potential health benefits.

In our study population, the lower risk of endometrial cancer associated with weight loss was more pronounced in women who were obese at baseline. We are not aware of other studies in which the associations of weight loss and endometrial cancer risk were stratified by BMI. However, our finding is consistent with reports that sustained weight loss after bariatric surgery has been associated with lower endometrial cancer risk in severely obese women. ${ }^{16-18}$

Most previous studies that have examined the relationship between absolute weight gain during adulthood and endometrial cancer risk have reported positive associations. ${ }^{4-6,19-21}$ We observed a significant positive association between weight gain $\geq 10$ pounds and endometrial cancer risk in women without hormone use. In the WHI randomized clinical trial on hormone therapy, estrogen plus progestin significantly reduced endometrial cancer incidence. ${ }^{22}$ In our current analyses, the lower risk of endometrial cancer associated with weight loss was more pronounced in women with estrogen plus progestin use. Somewhat in contrast, in several prior studies, postmenopausal hormone therapy use substantially attenuated the association between obesity and higher risk of endometrial cancer. $^{20,23,24}$

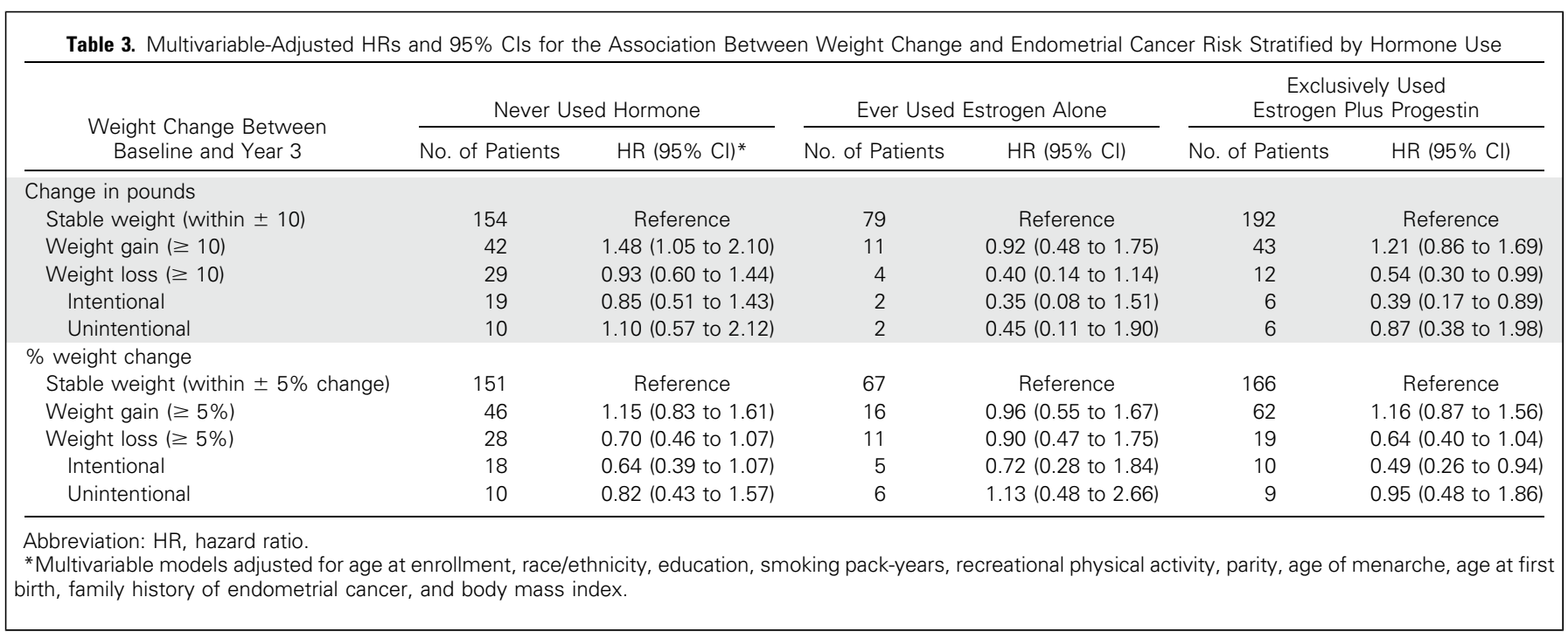


Strengths of this study include the large prospective design with long-term follow-up, centrally adjudicated endometrial cancer occurrences, detailed information on potential confounders, measured baseline and follow-up body weights, and determination of intentional or unintentional weight loss linked to the period of measured body weights. However, limitations deserve mention. Our findings are limited to postmenopausal women and did not account for weight change beyond 3 years of follow-up. If a woman lost weight between years 1 and 3 and then regained or even increased her weight, she was analyzed as a member of the weight loss group, a misclassification more likely to make our findings conservative.

In conclusion, intentional weight loss in postmenopausal women was associated with lower endometrial cancer risk, especially among women with obesity. These findings should motivate programs for weight loss in obese postmenopausal women.

\section{AUTHORS' DISCLOSURES OF POTENTIAL CONFLICTS} OF INTEREST

Disclosures provided by the authors are available with this article at jco.org.

\section{AUTHOR CONTRIBUTIONS}

Conception and design: Juhua Luo, Rowan T. Chlebowski, Michael Hendryx

Provision of study materials or patients: Rowan T. Chlebowski Collection and assembly of data: Juhua Luo, Rowan T. Chlebowski, Jean Wactawski-Wende

Data analysis and interpretation: All authors

Manuscript writing: All authors

Final approval of manuscript: All authors

Accountable for all aspects of the work: All authors

\section{REFERENCES}

1. American Cancer Society: Cancer facts and figures 2016. http://www.cancer.org/acs/groups/content/@ research/documents/document/acspc-047079.pdf

2. Lauby-Secretan B, Scoccianti C, Loomis D, et al: Body fatness and cancer: Viewpoint of the IARC Working Group. N Engl J Med 375:794-798, 2016

3. Parker ED, Folsom AR: Intentional weight loss and incidence of obesity-related cancers: The lowa Women's Health Study. Int J Obes Relat Metab Disord 27:1447-1452, 2003

4. Schouten LJ, Goldbohm RA, van den Brandt PA: Anthropometry, physical activity, and endometrial cancer risk: Results from the Netherlands Cohort Study. J Natl Cancer Inst 96:1635-1638, 2004

5. Trentham-Dietz A, Nichols HB, Hampton JM, et al: Weight change and risk of endometrial cancer. Int J Epidemiol 35:151-158, 2006

6. Nagle CM, Marquart L, Bain CJ, et al: Impact of weight change and weight cycling on risk of different subtypes of endometrial cancer. Eur J Cancer 49:2717-2726, 2013

7. McMinn J, Steel C, Bowman A: Investigation and management of unintentional weight loss in older adults. BMJ 342:d1732, 2011

8. Wijnhoven HA, van Zon SK, Twisk J, et al: Attribution of causes of weight loss and weight gain to 3-year mortality in older adults: Results from the
Longitudinal Aging Study Amsterdam. J Gerontol A Biol Sci Med Sci 69:1236-1243, 2014

9. The Women's Health Initiative Study Group: Design of the Women's Health Initiative clinical trial and observational study. Control Clin Trials 19: 61-109, 1998

10. Hays J, Hunt JR, Hubbell FA, et al: The Women's Health Initiative recruitment methods and results. Ann Epidemiol 13:S18-S77, 2003 (suppl)

11. Jackson RD, LaCroix AZ, Cauley JA, et al: The Women's Health Initiative calcium-vitamin D trial: Overview and baseline characteristics of participants. Ann Epidemiol 13:S98-S106, 2003 (suppl)

12. Langer RD, White $E$, Lewis $C E$, et al: The Women's Health Initiative observational study: Baseline characteristics of participants and reliability of baseline measures. Ann Epidemiol 13:S107-S121, 2003 (suppl)

13. Ritenbaugh C, Patterson RE, Chlebowski RT, et al: The Women's Health Initiative dietary modification trial: Overview and baseline characteristics of participants. Ann Epidemiol 13;S87-S97, 2003 (suppl)

14. Stefanick ML, Cochrane BB, Hsia J, et al: The Women's Health Initiative postmenopausal hormone trials: Overview and baseline characteristics of participants. Ann Epidemiol 13:S78-S86, 2003 (suppl)

15. Setiawan VW, Yang HP, Pike MC, et al: Type I and II endometrial cancers: Have they different risk factors? J Clin Oncol 31:2607-2618, 2013

16. McCawley GM, Ferriss JS, Geffel D, et al: Cancer in obese women: Potential protective impact of bariatric surgery. J Am Coll Surg 208:1093-1098, 2009
17. Sjöström L, Gummesson A, Sjöström CD, et al: Effects of bariatric surgery on cancer incidence in obese patients in Sweden (Swedish Obese Subjects Study): A prospective, controlled intervention trial. Lancet Oncol 10:653-662, 2009

18. Ward KK, Roncancio AM, Shah NR, et al: Bariatric surgery decreases the risk of uterine malignancy. Gynecol Oncol 133:63-66, 2014

19. Friedenreich $C$, Cust $A$, Lahmann $\mathrm{PH}$, et al: Anthropometric factors and risk of endometrial cancer: The European prospective investigation into cancer and nutrition. Cancer Causes Control 18:399-413, 2007

20. Chang SC, Lacey JV, Jr., Brinton LA, et al: Lifetime weight history and endometrial cancer risk by type of menopausal hormone use in the $\mathrm{NIH}$ AARP diet and health study. Cancer Epidemiol Biomarkers Prev 16:723-730, 2007

21. Park SL, Goodman MT, Zhang ZF, et al: Body size, adult $B M I$ gain, and endometrial cancer risk: The multiethnic cohort. Int J Cancer 126:490-499, 2010

22. Chlebowski RT, Anderson GL, Sarto GE, et al: Continuous combined estrogen plus progestin and endometrial cancer: The Women's Health Initiative randomized trial. J Natl Cancer Inst 108:djv350, 2015

23. McCullough $M L$, Patel $A V$, Patel $R$, et al: Body mass and endometrial cancer risk by hormone replacement therapy and cancer subtype. Cancer Epidemiol Biomarkers Prev 17:73-79, 2008

24. Crosbie EJ, Zwahlen M, Kitchener HC, et al: Body mass index, hormone replacement therapy, and endometrial cancer risk: A meta-analysis. Cancer Epidemiol Biomarkers Prev 19:3119-3130, 2010

\section{Affiliations}

Juhua Luo and Michael Hendryx, Indiana University Bloomington, IN; Rowan T. Chlebowski, University of California, Los Angeles, Medical Center, Torrance; Marcia Stefanick, Stanford University School of Medicine, Stanford, CA; Thomas Rohan, Albert Einstein College of Medicine, Bronx; Jean Wactawski-Wende, University at Buffalo, SUNY, Buffalo, NY; Cynthia A. Thomson, The University of Arizona, Tucson, AZ; Ashley S. Felix, The Ohio State University, Columbus, OH; Chu Chen, Fred Hutchinson Cancer Research Center; Wendy Barrington, University of Washington, Seattle, WA; Mace Coday, University of Tennessee Health Science Center, Memphis, TN; Erin LeBlanc, Kaiser Permanente Center for Health Research, Portland, OR; and Karen L. Margolis, Health Partners Institute, Minneapolis, MN

\section{Support}

The Women's Health Initiative (WHI) program is funded by the National Heart, Lung, and Blood Institute, National Institutes of Health, US Department of Health and Human Services through contracts No. HHSN268201600018C, HHSN268201600001C, HHSN268201600002C, HHSN268201600003C, and HHSN268201600004C. A short list of WHI investigators is in the Appendix (online only). 


\section{AUTHORS' DISCLOSURES OF POTENTIAL CONFLICTS OF INTEREST}

\section{Intentional Weight Loss and Endometrial Cancer Risk}

The following represents disclosure information provided by authors of this manuscript. All relationships are considered compensated. Relationships are self-held unless noted. I = Immediate Family Member, Inst = My Institution. Relationships may not relate to the subject matter of this manuscript. For more information about ASCO's conflict of interest policy, please refer to www.asco.org/rwc or ascopubs.org/jco/site/ifc.

\section{Juhua Luo}

No relationship to disclose

Rowan T. Chlebowski

No relationship to disclose

Michael Hendryx

No relationship to disclose

Thomas Rohan

Stock or Other Ownership: Metastat

Consulting or Advisory Role: Metastat

Patents, Royalties, Other Intellectual Property: Patent for tumor microenvironment of metastasis; patent for simultaneous DNA/RNA extraction from formalin-fixed paraffin-embedded samples

\section{Jean Wactawski-Wende}

No relationship to disclose

\section{Cynthia A. Thomson}

Honoraria: Today's Dietitian

\section{Ashley S. Felix}

No relationship to disclose

\section{Chu Chen}

No relationship to disclose

\section{Wendy Barrington}

No relationship to disclose

\section{Mace Coday}

No relationship to disclose

Marcia Stefanick

No relationship to disclose

\section{Erin LeBlanc}

Research Funding: Merck (Inst), Amgen (Inst), AstraZeneca (Inst), Bristol-Myers Squibb (Inst)

Karen L. Margolis

Consulting or Advisory Role: Novartis Pharmaeuticals (Inst) 


\section{Appendix}

\section{Short List of Women's Health Initiative Investigators}

Program office (National Heart, Lung, and Blood Institute, Bethesda, Maryland) investigators: Jacques Rossouw, Shari Ludlam, Joan McGowan, Leslie Ford, and Nancy Geller

Clinical Coordinating Center (Fred Hutchinson Cancer Research Center, Seattle, WA) investigators: Garnet Anderson, Ross Prentice, Andrea LaCroix, and Charles Kooperberg

Individual academic center investigators: JoAnn E. Manson (Brigham and Women's Hospital, Harvard Medical School, Boston, MA); Barbara V. Howard (MedStar Health Research Institute/Howard University, Washington, DC); Marcia L. Stefanick (Stanford Prevention Research Center, Stanford, CA); Rebecca Jackson (The Ohio State University, Columbus, OH); Cynthia A. Thomson (University of Arizona, Tucson/Phoenix, AZ); Jean Wactawski-Wende (University at Buffalo, Buffalo, NY); Marian Limacher (University of Florida, Gainesville/Jacksonville, FL); Jennifer Robinson (University of Iowa, Iowa City/Davenport, IA); Lewis Kuller (University of Pittsburgh, Pittsburgh, PA); Sally Shumaker (Wake Forest University School of Medicine, Winston-Salem, NC); Robert Brunner (University of Nevada, Reno, NV); and Karen L. Margolis (University of Minnesota, Minneapolis, MN)

Women's Health Initiative memory study (Wake Forest University School of Medicine, Winston-Salem, NC) investigator: Mark Espeland

For a list of all the investigators who have contributed to WHI science, please visit https://www.whi.org/researchers/Documents \%20\%20Write\%20a\%20Paper/WHI\%20Investigator\%20Long\%20List.pdf. 


\begin{tabular}{|c|c|c|c|c|c|c|c|c|c|c|}
\hline \multirow[b]{4}{*}{ Characteristic } & \multicolumn{10}{|c|}{$\%$ Weight Change* $(\mathrm{N}=36,793)$} \\
\hline & \multirow{2}{*}{\multicolumn{2}{|c|}{$\begin{array}{l}\text { Stable Weight } \\
\text { (within 5\%) }\end{array}$}} & \multirow{2}{*}{\multicolumn{2}{|c|}{ Weight Gain $(\geq 5 \%)$}} & \multicolumn{6}{|c|}{ Weight Loss } \\
\hline & & & & & \multicolumn{2}{|l|}{$\geq 5 \%$} & \multicolumn{2}{|c|}{ Unintentional } & \multicolumn{2}{|c|}{ Intentional } \\
\hline & $\begin{array}{l}\text { No. of Patients } \\
(n=24,863)\end{array}$ & $\begin{array}{l}\text { Mean } \\
\text { or } \%\end{array}$ & $\begin{array}{l}\text { No. of Patients } \\
\quad(n=7,159)\end{array}$ & $\begin{array}{l}\text { Mean } \\
\text { or \% }\end{array}$ & $\begin{array}{l}\text { No. of Patients } \\
(n=4,771)\end{array}$ & $\begin{array}{l}\text { Mean } \\
\text { or } \%\end{array}$ & $\begin{array}{l}\text { No. of Patients } \\
\quad(n=1,856)\end{array}$ & $\begin{array}{l}\text { Mean } \\
\text { or } \%\end{array}$ & $\begin{array}{l}\text { No. of Patients } \\
\quad(n=2,915)\end{array}$ & $\begin{array}{l}\text { Mean } \\
\text { or \% }\end{array}$ \\
\hline Mean age at screening, years & & 63.5 & & 61.4 & & 64.3 & & 65.9 & & 63.3 \\
\hline Mean $\mathrm{BMI}, \mathrm{kg} / \mathrm{m}^{2}$ & & 26.4 & & 26.5 & & 28.8 & & 27.5 & & 29.6 \\
\hline Total METs per week & & 15.2 & & 14.4 & & 13.3 & & 12.3 & & 13.9 \\
\hline \multicolumn{11}{|l|}{ Ethnicity } \\
\hline $\begin{array}{l}\text { American Indian or Alaskan } \\
\text { Native }\end{array}$ & 70 & 0.3 & 35 & 0.5 & 18 & 0.4 & 7 & 0.4 & 11 & 0.4 \\
\hline Asian or Pacific Islander & 891 & 3.6 & 188 & 2.6 & 121 & 2.5 & 55 & 3.0 & 66 & 2.3 \\
\hline Black or African-American & 1,221 & 4.9 & 395 & 5.5 & 304 & 6.4 & 122 & 6.6 & 182 & 6.2 \\
\hline Hispanic/Latino & 702 & 2.8 & 223 & 3.1 & 140 & 2.9 & 51 & 2.7 & 89 & 3.1 \\
\hline White (not of Hispanic origin) & 21,637 & 87.0 & 6,230 & 87.0 & 4,135 & 86.7 & 1,597 & 86.0 & 2,538 & 87.1 \\
\hline Other & 342 & 1.4 & 88 & 1.2 & 53 & 1.1 & 24 & 1.3 & 29 & 1.0 \\
\hline $\begin{array}{l}\text { Education } \\
\text { High school diploma or less }\end{array}$ & 4,399 & 17.7 & 1,293 & 18.1 & 900 & 18.9 & 368 & 19.8 & 532 & 18.3 \\
\hline $\begin{array}{l}\text { Some college/technical } \\
\text { training }\end{array}$ & 8,127 & 32.7 & 2,462 & 34.4 & 1,748 & 36.6 & 676 & 36.4 & 1,072 & 36.8 \\
\hline College graduate or more & 6,726 & 27.1 & 1,845 & 25.8 & 1,177 & 24.7 & 466 & 25.1 & 711 & 24.4 \\
\hline Masters degree or more & 5,611 & 22.6 & 1,559 & 21.8 & 946 & 19.8 & 346 & 18.6 & 600 & 20.6 \\
\hline $\begin{array}{l}\text { Pack-years of cigarette smoking } \\
\text { Missing }\end{array}$ & 757 & 3.0 & 232 & 3.2 & 139 & 2.9 & 52 & 2.8 & 87 & 3.0 \\
\hline Never smoking & 12,864 & 51.7 & 3,385 & 47.3 & 2334 & 48.9 & 947 & 51.0 & 1,387 & 47.6 \\
\hline$<10$ & 5,083 & 20.4 & 1,415 & 19.8 & 914 & 19.2 & 308 & 16.6 & 606 & 20.8 \\
\hline 10 to $<20$ & 2,166 & 8.7 & 707 & 9.9 & 387 & 8.1 & 155 & 8.4 & 232 & 8.0 \\
\hline 20 to $<30$ & 1,368 & 5.5 & 471 & 6.6 & 307 & 6.4 & 124 & 6.7 & 183 & 6.3 \\
\hline 30 to $<40$ & 1,121 & 4.5 & 380 & 5.3 & 241 & 5.1 & 87 & 4.7 & 154 & 5.3 \\
\hline$\geq 40$ & 1,504 & 6.0 & 569 & 7.9 & 449 & 9.4 & 183 & 9.9 & 266 & 9.1 \\
\hline $\begin{array}{l}\text { Relative had endometrial cancer } \\
\text { Missing }\end{array}$ & 13,838 & 55.7 & 3,993 & 55.8 & 2,654 & 55.6 & 1,043 & 56.2 & 1,611 & 55.3 \\
\hline No & 9,815 & 39.5 & 2,843 & 39.7 & 1,860 & 39.0 & 714 & 38.5 & 1,146 & 39.3 \\
\hline Yes & 1,210 & 4.9 & 323 & 4.5 & 257 & 5.4 & 99 & 5.3 & 158 & 5.4 \\
\hline $\begin{array}{l}\text { History of hormone therapy use } \\
\text { Never HRT use }\end{array}$ & 12,165 & 48.9 & 3,196 & 44.6 & 2,549 & 53.4 & 1010 & 54.4 & 1,539 & 52.8 \\
\hline Estrogen alone use & 1,672 & 6.7 & 454 & 6.3 & 322 & 6.7 & 160 & 8.6 & 162 & 5.6 \\
\hline Estrogen plus progestin use & 9,621 & 38.7 & 3,099 & 43.3 & 1,665 & 34.9 & 593 & 32.0 & 1,072 & 36.8 \\
\hline $\begin{array}{l}\text { Estrogen alone and estrogen } \\
\text { plus progestin use }\end{array}$ & 1,405 & 5.7 & 410 & 5.7 & 235 & 4.9 & 93 & 5.0 & 142 & 4.9 \\
\hline $\begin{array}{l}\text { Age at menarche, years } \\
\text { Missing }\end{array}$ & 3,762 & 15.1 & 1,083 & 15.1 & 738 & 15.5 & 276 & 14.9 & 462 & 15.8 \\
\hline$<12$ & 2,625 & 10.6 & 848 & 11.8 & 545 & 11.4 & 183 & 9.9 & 362 & 12.4 \\
\hline $12-13$ & 9,784 & 39.4 & 2,818 & 39.4 & 1,927 & 40.4 & 780 & 42.0 & 1,147 & 39.3 \\
\hline $14-15$ & 5,721 & 23.0 & 1,539 & 21.5 & 1,014 & 21.3 & 387 & 20.9 & 627 & 21.5 \\
\hline$\geq 16$ & 2,971 & 11.9 & 871 & 12.2 & 547 & 11.5 & 230 & 12.4 & 317 & 10.9 \\
\hline $\begin{array}{l}\text { No. of term pregnancies } \\
\text { Never pregnant }\end{array}$ & 2,686 & 10.8 & 799 & 11.2 & 582 & 12.2 & 232 & 12.5 & 350 & 12.0 \\
\hline Never had term pregnancy & 663 & 2.7 & 228 & 3.2 & 135 & 2.8 & 56 & 3.0 & 79 & 2.7 \\
\hline 1 & 2,115 & 8.5 & 646 & 9.0 & 432 & 9.1 & 157 & 8.5 & 275 & 9.4 \\
\hline 2 & 6,562 & 26.4 & 2,019 & 28.2 & 1,216 & 25.5 & 456 & 24.6 & 760 & 26.1 \\
\hline 3 & 6,141 & 24.7 & 1,693 & 23.6 & 1,090 & 22.8 & 404 & 21.8 & 686 & 23.5 \\
\hline 4 & 3,602 & 14.5 & 982 & 13.7 & 670 & 14.0 & 283 & 15.2 & 387 & 13.3 \\
\hline$\geq 5$ & 3,094 & 12.4 & 792 & 11.1 & 646 & 13.5 & 268 & 14.4 & 378 & 13.0 \\
\hline $\begin{array}{l}\text { Age at first birth, years } \\
\text { Missing }\end{array}$ & 2,164 & 8.7 & 598 & 8.4 & 376 & 7.9 & 135 & 7.3 & 241 & 8.3 \\
\hline Never had term pregnancy & 3,349 & 13.5 & 1,027 & 14.3 & 717 & 15.0 & 288 & 15.5 & 429 & 14.7 \\
\hline$<20$ & 1,813 & 7.3 & 721 & 10.1 & 439 & 9.2 & 186 & 10.0 & 253 & 8.7 \\
\hline $20-29$ & 15,187 & 61.1 & 4,240 & 59.2 & 2,781 & 58.3 & 1,074 & 57.9 & 1,707 & 58.6 \\
\hline$\geq 30$ & 2,350 & 9.5 & 573 & 8.0 & 458 & 9.6 & 173 & 9.3 & 285 & 9.8 \\
\hline
\end{tabular}


Intentional Weight Loss and Endometrial Cancer

Table A2. HRs and 95\% Cls for the Association Between BMI Change and Risk of Endometrial Cancer

BMI (kg/m2) Change Between Baseline and Year 3

Low stable BMIt

Weight gain or stay high BMI¥

Weight loss§

Intentional

Unintentional
No. of Patients

186
358
22
9
13

Multivariable-Adjusted HR $(95 \% \mathrm{Cl})^{*}$ Reference $1.46(1.22$ to 1.75$)$ $0.97(0.14$ to 6.93$)$

$0.74(0.38$ to 1.44$)$ 2.09 (1.19 to 3.67$)$

Abbreviations: BMI, body mass index; HR, hazard ratio.

${ }^{*}$ Multivariable models adjusted for age at enrollment, race/ethnicity, education, smoking pack-years, recreational physical activity, parity, age of menarche, age at first birth, family history of endometrial cancer, and BMI.

$+\mathrm{BMI}<25 \mathrm{~kg} / \mathrm{m}^{2}$ at both baseline and year 3 .

$\neq B M I<25 \mathrm{~kg} / \mathrm{m}^{2}$ at baseline and BMI $\geq 25 \mathrm{~kg} / \mathrm{m}^{2}$ at year 3 , or BMI $\geq 25 \mathrm{~kg} / \mathrm{m}^{2}$ at both baseline and year 3 .

$\S B M I \geq 25 \mathrm{~kg} / \mathrm{m}^{2}$ at baseline and $\mathrm{BMI}<25 \mathrm{~kg} / \mathrm{m}^{2}$ at year 3 . 